\title{
Virtual Testing of Material Heating for a Semi-Solid Forming Process
}

\author{
Mária Behúlová*
}

\begin{abstract}
The research in the field of forming processes is focused on the development of novel progressive technologies leading to the significant enhancement of production efficiency and quality of final products by concurrent decrease in manufacturing costs and energy requirements on single production operations.
\end{abstract}

Considerable microstructure refinement and homogenity increase belong to the typical consequences of rapid cooling and non-equilibrium solidification of melts. The fundamental physical and metallurgical principles of rapid solidification processing can be exploited by the manufacturing of small products using the forming in semi-solid state. Thixoforming requires the material heating to higher temperatures in comparison with conventional hot forming technologies. However, considering the small volumes of heated material, effective direct electrical heating methods, induction heating or heating in electromagnetic levitation can be exploited with many advantages. After semiproduct heating to the temperatures between solidus and liquidus, the material is formed in an open or closed die ensuring the intensive heat extraction from treated material and its rapid solidification. As a result of the forming in semi-solid state, the product with very accurate shape, fine microstructure and specific material properties can be obtained.

The paper deals with the computer testing of direct electric heating of high alloyed tool steel for a semi-solid forming process using the program code ANSYS. The influence of chosen geometrical and technological parameters on the temperature distribution in heated semiproducts is evaluated.

Keywords: forming, semi-solid state, temperature fields, direct electric heating, numerical simulation, ANSYS

\section{Introduction}

Semi-solid forming belongs to the relatively new near-net-shape technologies dedicated for manufacturing products with complex geometries and significantly improved material properties [1-3]. Semi-solid metal forming takes place at temperatures between solidus and liquidus temperatures. As a result of this, it combines advantages of both metal forging and metal casting processes. Comparing with conventional die casting, it provides possibility to produce parts with substantially higher quality but on the other hand cheaper than using

\footnotetext{
* Senior lecturer, RNDr. Mária Behúlová, PhD., Slovak University of Technology in Bratislava, Faculty of Materials Science and Technology in Trnava, Paulinska 16, 91724 Trnava, Slovak Republic, Tel.: +421 33 5511601, e-mail: maria.behulova@stuba.sk
} 
classical forging processes. Lower processing temperature and non-turbulent flow of semisolid material lead to a quite low degree of shrinkage and porosity of final products $[3,4]$.

Moreover, the shear rate dependent viscosity of semi-solid materials allows to produce rather complicated geometries applying single forming operation with considerably lower forces than in conventional hot forging [5]. To obtain very fine and homogeneous microstructure, it is necessary to apply deformation at the temperatures when the initial slurry material consists of accurately defined portions of liquid and solid phases, typically of $40 \%$ liquid and $60 \%$ solid [4, 6-7]. Solid particles with non-dendritic globular shape should be uniformly distributed in the liquid phase.

Except of low temperature aluminum and magnesium alloys, the great attention is paid in the last years to the semi-solid forming of steels [3, 5-9]. High temperatures connected with semisolid steel forming processing require the exploitation of suitable tool materials. Specific heating control is also necessary to maintain the proper temperature of material with required fractions of liquid and solid phases.

This paper is aimed at the numerical simulation and virtual testing of direct electric heating of semiproducts from the $\mathrm{X} 210 \mathrm{Cr} 12$ steel before their semi-solid forming. The heating process is realised directly in a die. The influence of chosen geometrical and technological parameters on the temperature distribution in heated semiproducts is examined.

\section{Experimental Equipment and Material}

Experimental die for semi-solid material forming consists of two parts which are after bolting inserted into the forming machine. A semiproduct is heated up through copper electrodes using direct electric heating. After heating, it is pressed down and the semi-solid material will fill a die cavity.

According to good thixotropic behaviour, the $\mathrm{X} 210 \mathrm{Cr} 12$ steel (Table 1) was chosen as an experimental material. Applying the program code JMatPro, the dependence of liquid fraction on the temperature for this steel was calculated (Fig. 1) [7]. The X210Cr12 steel starts to melt at the temperature of $1225^{\circ} \mathrm{C}$. The temperature interval from $1290^{\circ} \mathrm{C}$ to $1330^{\circ} \mathrm{C}$ corresponds to the liquid fraction of 40-60 \% suitable for semi-solid forming. It means that before forming, the material should be heated up to the temperature from this range. Moreover, solid particles should have globular shape.

Table 1. Chemical composition of X210Cr12 experimental steel

\begin{tabular}{|c|c|c|c|c|c|c|}
\hline $\mathrm{C}$ & $\mathrm{Cr}$ & $\mathrm{Mn}$ & $\mathrm{Si}$ & $\mathrm{Ni}$ & $\mathrm{P}$ & $\mathrm{S}$ \\
\hline 1.8 & 11 & 0.2 & 0.2 & 0.5 & 0.03 & 0.035 \\
\hline
\end{tabular}




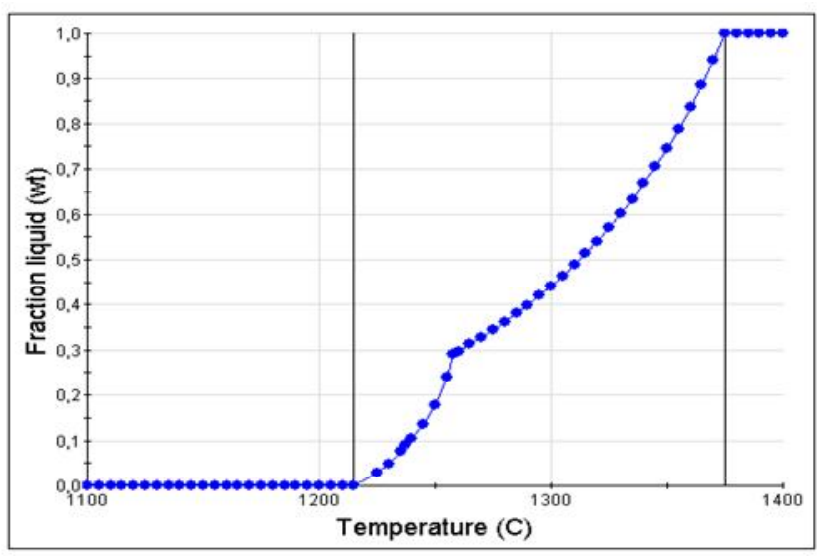

Fig. 1. Dependence of liquid fraction on the temperature

\section{Simulation Model}

Numerical analysis and simulation of direct electric heating of semiproducts to the thixoforming temperature were performed by the finite element code ANSYS 10.0 using solution of coupled electric and thermal problems [10-12]. Coupling of electric and thermal analyses by direct electrical heating (Fig. 2) is determined by the temperature dependence of electrical properties of heated material and on the other hand by the dependence of generated Joule heat on electrical properties. Joule heat as a result of electric analysis represents the load (internal energy source) for transient thermal analysis. Computed temperature distribution creates input data for the following electric analysis.

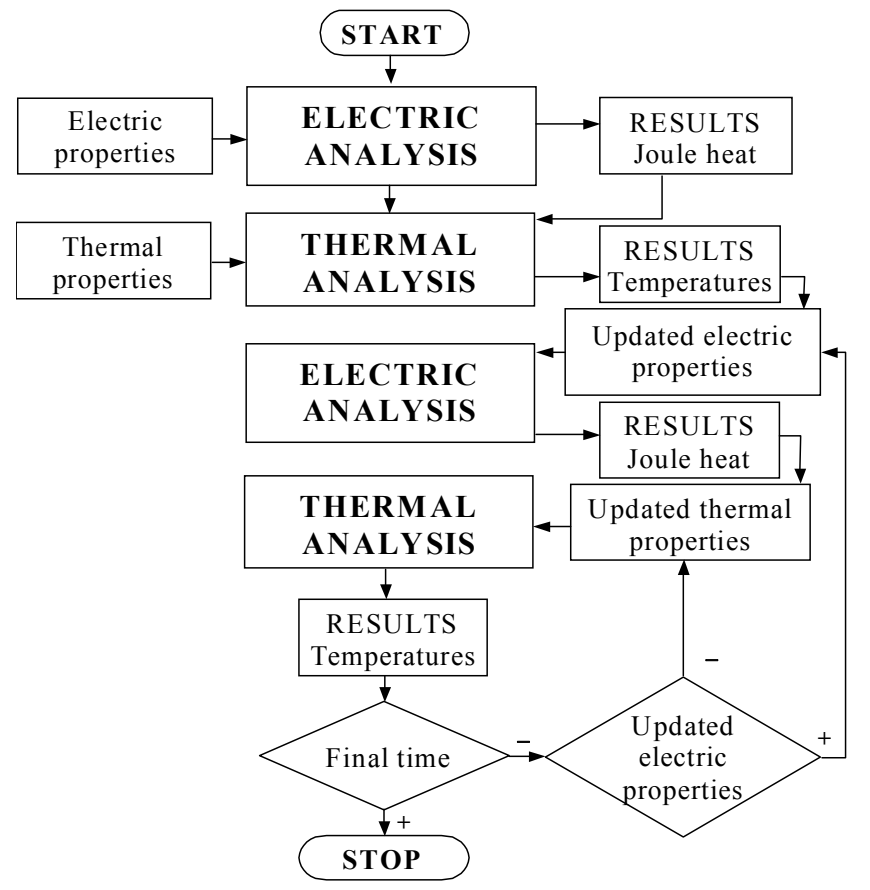

Fig. 2. Scheme of the solution of coupled electric and thermal problem

Analysis of electric fields is based on the solution of Laplace equation in the form [13]

$\operatorname{div}(\sigma \operatorname{grad} V)=0$ 
where $\sigma$ is electric conductivity and $V$ electric potential.

Transient temperature field in solids can be described by Fourier-Kirchhoff partial differential equation $[14,15]$

$c \rho \frac{\partial T}{\partial t}=\operatorname{div}(\lambda \operatorname{grad} T)+q_{v}$,

in which $\rho$ is the density, $c$ is the specific heat capacity, $\lambda$ is the thermal conductivity and $q_{\mathrm{v}}$ is the volume density of internal heat sources, i. e. the heat generated in unit volume per second. By resistance heating this term corresponds to the Joule heat.

For the analysis of temperature fields by direct electric heating, three experimental semiproducts of cylindrical shape with the diameters of $6 \mathrm{~mm}$ and the high of $22 \mathrm{~mm}, 26 \mathrm{~mm}$ and $28 \mathrm{~mm}$ respectively, were considered (Fig. 3a). The semiproducts have end in the form of the frustum of the cone.

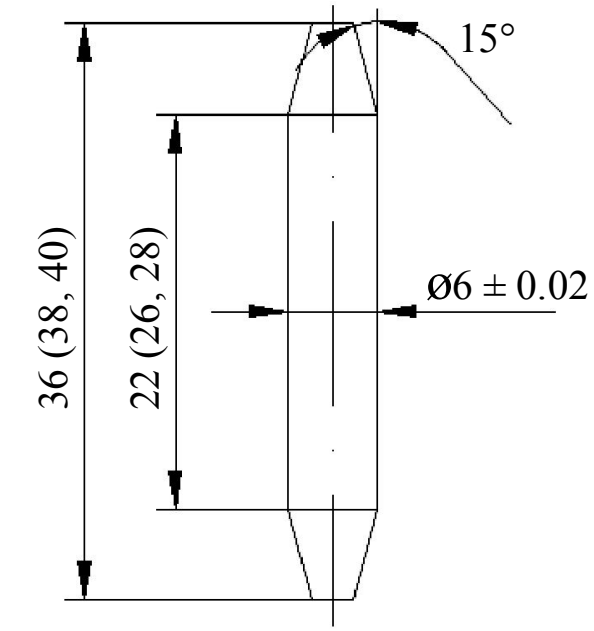

a)

b)

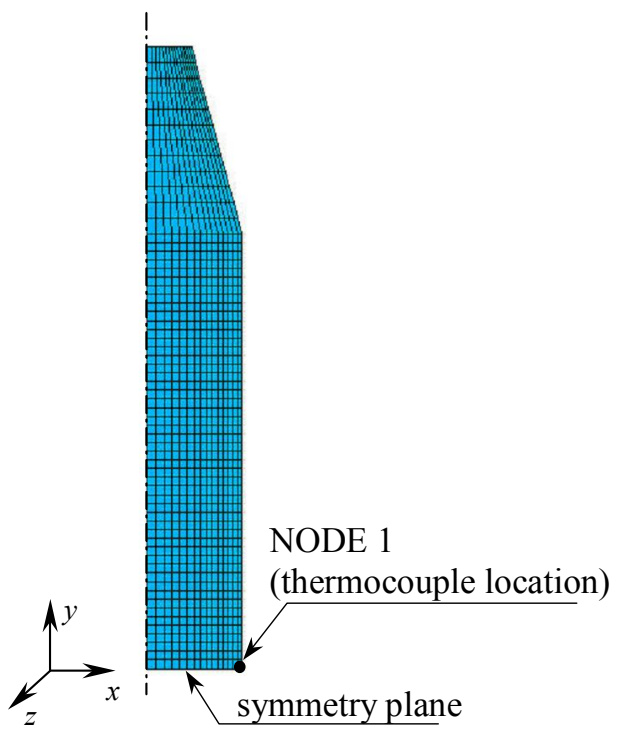

Fig. 3. Geometrical and FEM model of experimental semiproduct

Copper electrodes were modeled without construction details (threads, curvatures...). Finite elements models of the semiproduct (Fig. 3b) and a die were simplified to the plane- and axisymmetric. Thermal and electric properties of the X210Cr12 steel (Fig. 4) were obtained using the program code JMatPro. Temperature dependent material properties of a die, copper electrodes and air according to [15-17] were used. Values of emmisivity for single materials were considered to be constant: $\varepsilon_{\text {steel }}=0.8 ; \varepsilon_{\text {die }}=0.3 \mathrm{a} \varepsilon_{\mathrm{Cu}}=0.037$.

The initial temperature of materials was supposed to be $20^{\circ} \mathrm{C}$. The copper electrode was on the top surface loaded by the time dependent voltage. Neutral voltage was defined at the semiproduct in the symmetry plane. In the narrow space filled by air, the heat transfer only by conduction was considered. The radiative heat transfer was taken into account mutually between semiproduct, die and electrodes. Copper electrodes were in the area of threads cooled by water. Other surface areas of electrodes and a die were cooled down by free convection and radiation to the surrounding air with the temperature of $20^{\circ} \mathrm{C}$. 


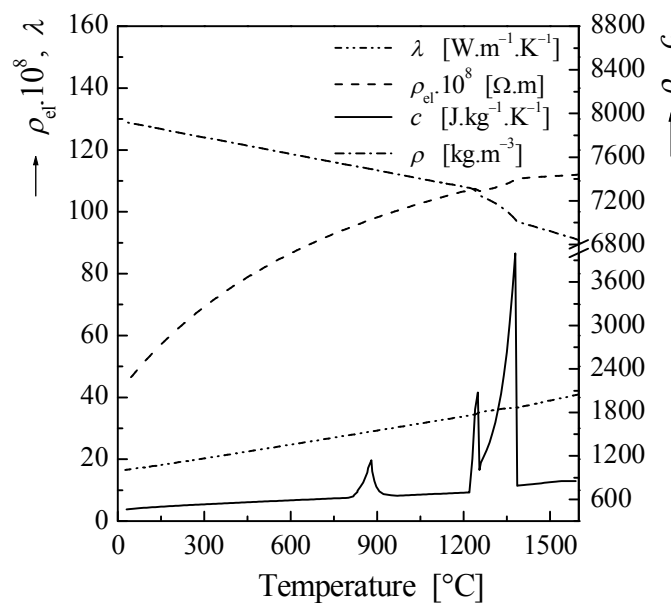

\begin{tabular}{|c|c|c|c|c|c|c|}
\hline $\begin{array}{c}\text { Material } \\
\text { property at } \\
\text { the } T\left[{ }^{\circ} \mathrm{C}\right]\end{array}$ & $\mathbf{D i e}$ & \multicolumn{5}{|c|}{ Electrodes } \\
\cline { 2 - 7 } & $\mathbf{2 0}$ & $\mathbf{0}$ & $\mathbf{1 0 0}$ & $\mathbf{2 0 0}$ & $\mathbf{4 0 0}$ & $\mathbf{6 0 0}$ \\
\hline $\begin{array}{c}\lambda \\
{\left[\mathrm{W} . \mathrm{m}^{-1} \mathrm{~K}^{-1}\right]}\end{array}$ & 16.4 & 386.1 & 379.1 & 373.3 & 364.2 & 353.6 \\
\hline $\begin{array}{c}\rho \\
{\left[\mathrm{kg} . \mathrm{m}^{-3}\right]}\end{array}$ & 4510 & 8930 & 8914 & 8898 & 8865 & 8832 \\
\hline $\begin{array}{c}c \\
{\left[\mathrm{~J} . \mathrm{kg}^{-1} \mathrm{~K}^{-1}\right]}\end{array}$ & 523 & 379 & 385 & 389 & 403 & 427 \\
\hline $\begin{array}{c}\rho_{\mathrm{el}} \cdot 0^{8} \\
{[\Omega . \mathrm{m}]}\end{array}$ & 52 & 1.71 & - & 2.93 & - & 4.6 \\
\hline
\end{tabular}

Fig. 4. Thermal and electric properties of the X210Cr12 steel, die and copper electrodes

Developed simulation model was verified using experimental temperature measurements by direct electric heating of the semiproduct with the length of $40 \mathrm{~mm}$. Measured temperatures were compared with temperatures computed in the node corresponding to the thermocouple location (Fig. 5a). The mean relative deviation of measured and calculated temperatures is $0.54 \%$ with the maximum of $6.9 \%$ at the beginning of the heating process (Fig. $5 \mathrm{~b}$ ).
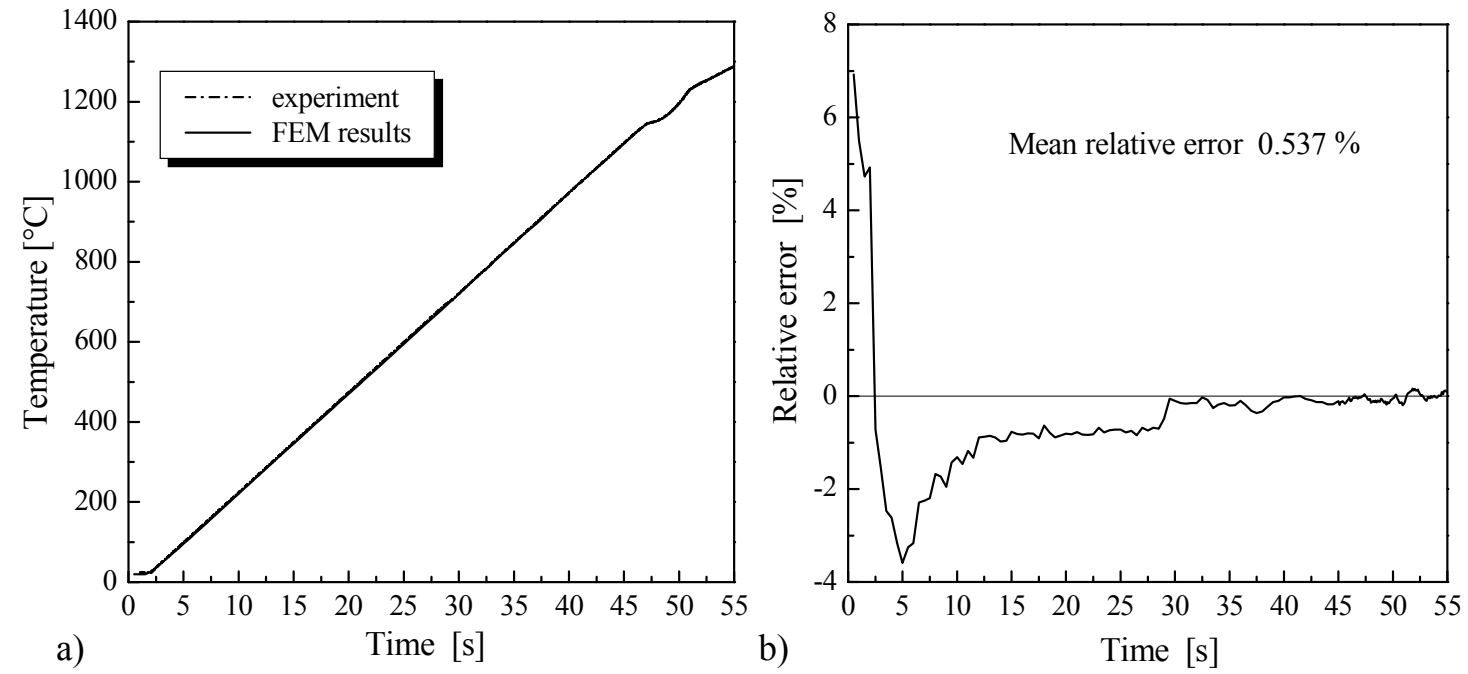

Fig. 5. Time history of a) measured and calculated temperatures and b) relative error of calculated temperatures

\section{Analysis of Temperature Fields by Direct Electrical Heating before Forming}

Based on the described simulation model, the analysis of temperature fields was carried out with the aim to found out the influence of chosen heating parameters on the temperature distribution in a heated semiproduct and the volume of semi-solid material with the temperature from the required temperature interval from $1290{ }^{\circ} \mathrm{C}$ to $1330{ }^{\circ} \mathrm{C}$. Using numerical experiments, the influence of following parameters on the temperature fields in the semiproduct was investigated:

- the heating rate to the solidus temperature,

- the holding time at the temperature above solidus temperature,

- geometrical characteristics of a semiproduct. 


\subsection{Influence of the heating rate on the temperature fields in a semiproduct}

The semiproduct with the length of $40 \mathrm{~mm}$ (Fig. 3a) was heated up with the average heating rate of $12.5 \mathrm{~K} . \mathrm{s}^{-1}, 23 \mathrm{~K} . \mathrm{s}^{-1}$ and $46 \mathrm{~K} . \mathrm{s}^{-1}$. The heating rate of $23 \mathrm{~K} . \mathrm{s}^{-1}$ corresponds to the average heating rate by performed experimental temperature measurement. The voltage rise was supposed to be linear after the second second (Fig. 6a). Resulting temperature increase in the node 1 is depicted in Fig. 6 b.

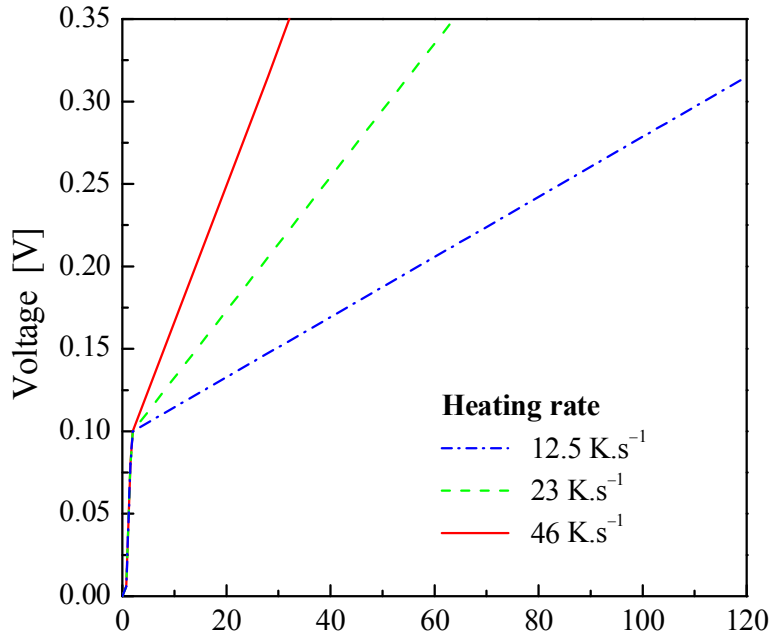

a)

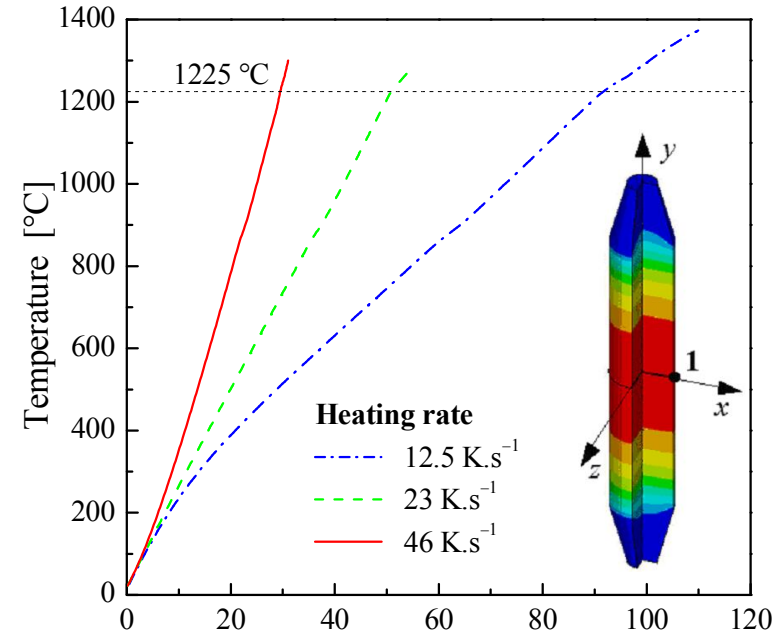

b)

Time $[\mathrm{s}]$

Fig. 6. Time dependence of a) applied voltage and b) temperatures in the node 1 for the analysed heating rates

a)

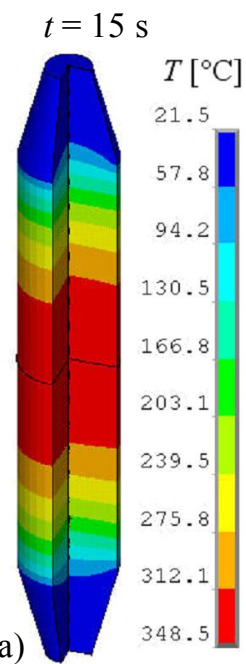

b)

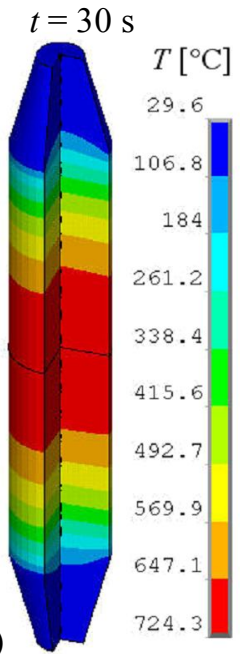

c)

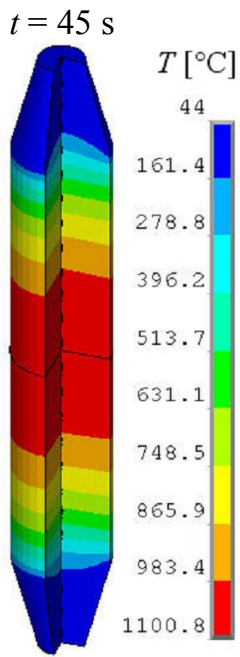

d)

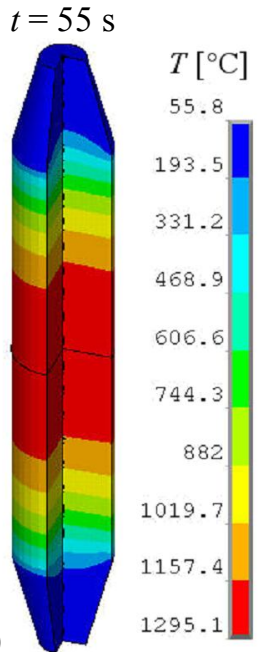

Fig. 7. Temperature distribution in the semiproduct in the time of a) 15 seconds, b) 30 seconds, c) 45 seconds and d) 55 seconds

The temperature distribution in the semiproduct heated up with the heating rate of $23 \mathrm{~K} . \mathrm{s}^{-1}$ after chosen heating periods is illustrated in Fig. 7. The heating process is uniform, maximal temperatures in the conical part of a semiproduct are lower than $200{ }^{\circ} \mathrm{C}$.

Figure 8 documents the dependence of temperatures along rotation axis for chosen heating rates in the moment when the temperature in the semiproduct centre of gravity reaches $1330^{\circ} \mathrm{C}$. The increase in heating rate results in the enlargement of mushy zone. For the die filling and attainment of required microstructure and material properties of the final product, the maximal volume of molten material before deformation is requested. The volume of semisolid material increases with the increase in heating rate from $140 \mathrm{~mm}^{3}$ to $160 \mathrm{~mm}^{3}$ (Table 2). 
The volume of material with the temperatures from the recommended temperature interval for thixoforming from $1290^{\circ} \mathrm{C}$ to $1330^{\circ} \mathrm{C}$ is maximal $\left(102.21 \mathrm{~mm}^{3}\right)$ by the heating rate of $46 \mathrm{~K} \cdot \mathrm{s}^{-1}$. However, it is necessary to be aware that the solidus temperature shifts to higher values by increased heating rate [8]. In this reason, it is recommended to perform DTA experiments with the aim to specify the dependence of solidus temperature on the heating rate.

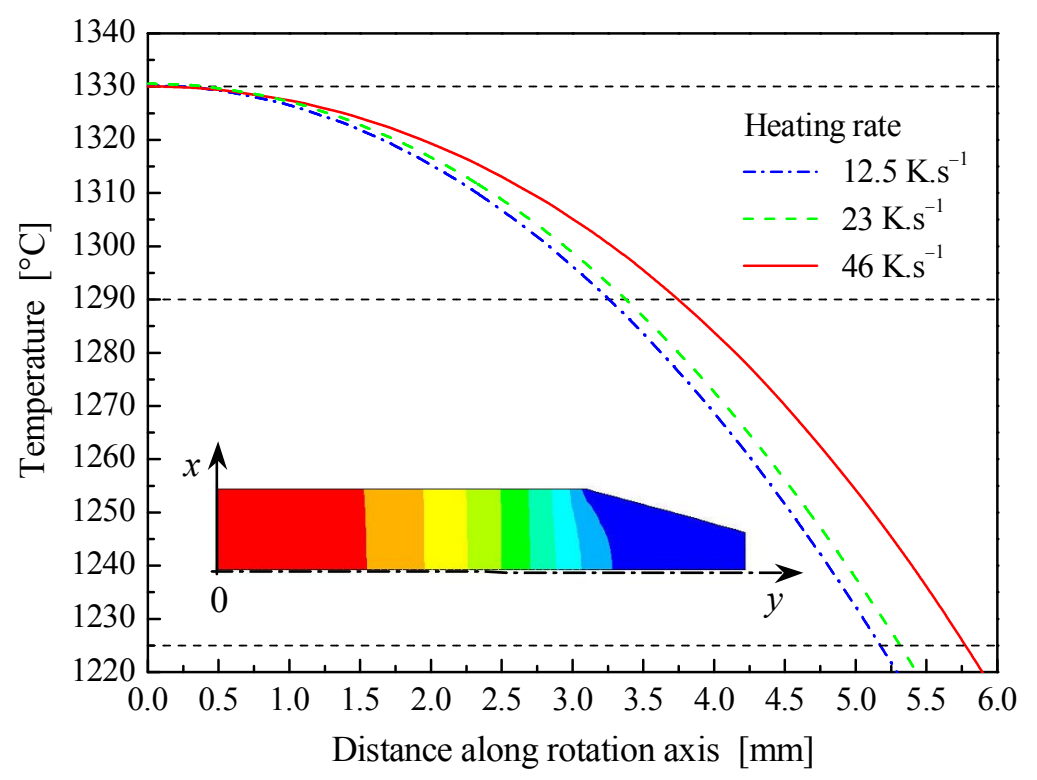

Fig. 8. Temperature distribution along the rotational axis in the time when the temperature in the centre of gravity reaches $1330^{\circ} \mathrm{C}$

Table 2. Dependence of the volume of semi-solid material on the heating rate

\begin{tabular}{|l|c|c|c|}
\hline \multirow{2}{*}{ Volume of the material with the temperature } & \multicolumn{3}{|c|}{ Heating rate } \\
\cline { 2 - 4 } & $\mathbf{1 2 . 5} \mathbf{~ K . s}^{\mathbf{- 1}}$ & $\mathbf{2 3 ~ \mathbf { K . s } ^ { - 1 }}$ & $\mathbf{4 6 ~ \mathbf { K . s } ^ { \mathbf { - 1 } }}$ \\
\hline above solidus temperature $\left[\mathrm{mm}^{3}\right]$ & 142.43 & 149.71 & 160.24 \\
\hline in the interval from $1290^{\circ} \mathrm{C}$ to $1330^{\circ} \mathrm{C}\left[\mathrm{mm}^{3}\right]$ & 88.40 & 91.48 & 102.21 \\
\hline
\end{tabular}

\subsection{Influence of the holding time on the temperature fields in a semiproduct}

The semiproduct with the high of $40 \mathrm{~mm}$ was heated up during the time of 60 seconds to the temperature of $1308^{\circ} \mathrm{C}$ in the node 1 , i. e. in the position of temperature measurement by thermocouple. After this time period, the surface temperature in the node 1 remains constant by the time of 120 seconds (Fig. 9). The temperature increase in the axis of a semiproduct (Fig. 10) and the volume of semi-solid material was investigated.

Extension of holding time results in a slight temperature rise in the rotation axis, each $10^{\circ}$ seconds approximately by $1^{\circ} \mathrm{C}$. The volume of semi-solid material with the temperature above solidus temperature of $1225^{\circ} \mathrm{C}$ does not change during considered holding time (Fig. 9). Only the volume of material with the temperature from the temperature interval from $1290^{\circ} \mathrm{C}$ to $1330^{\circ} \mathrm{C}$ slightly increases from $58.6 \mathrm{~mm}^{3}$ to $63.2 \mathrm{~mm}^{3}$ by the extension of holding time from 30 seconds to 60 seconds. 


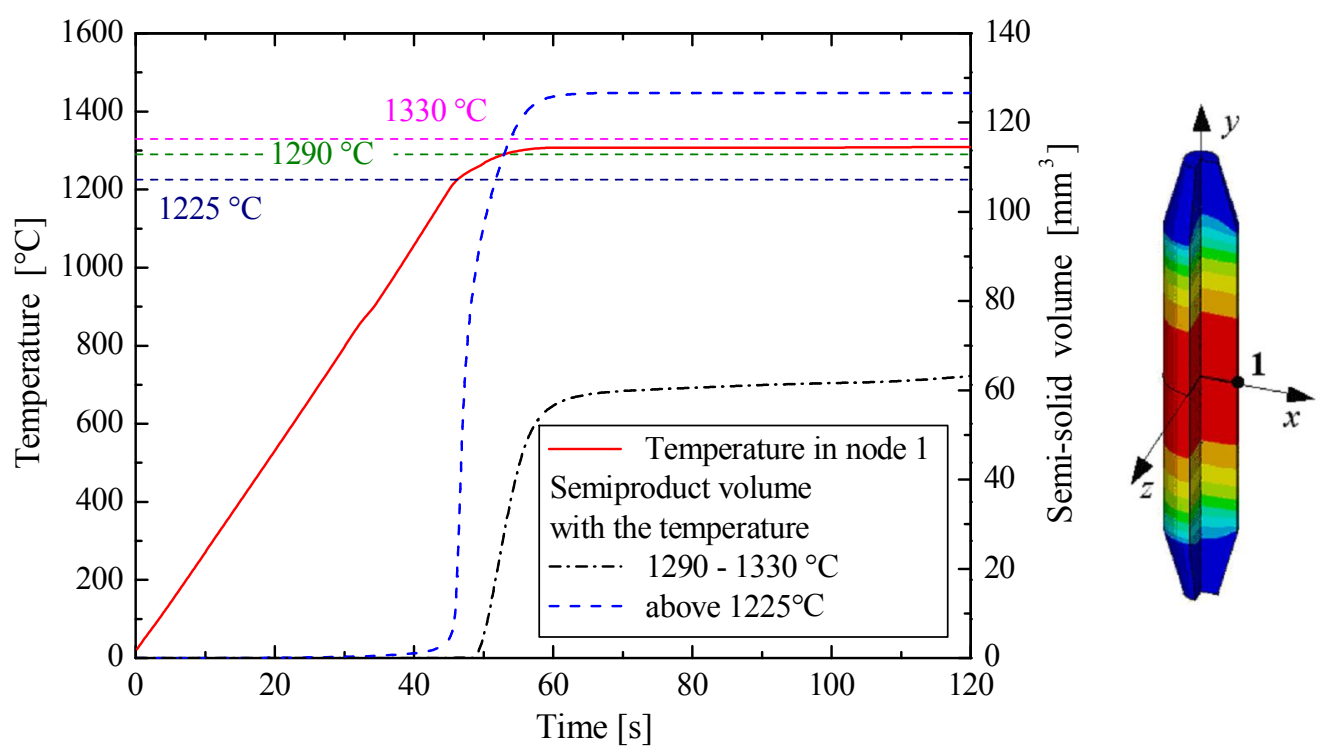

Fig. 9. Time dependence of temperature in the node 1 and of the volume of semi-solid material

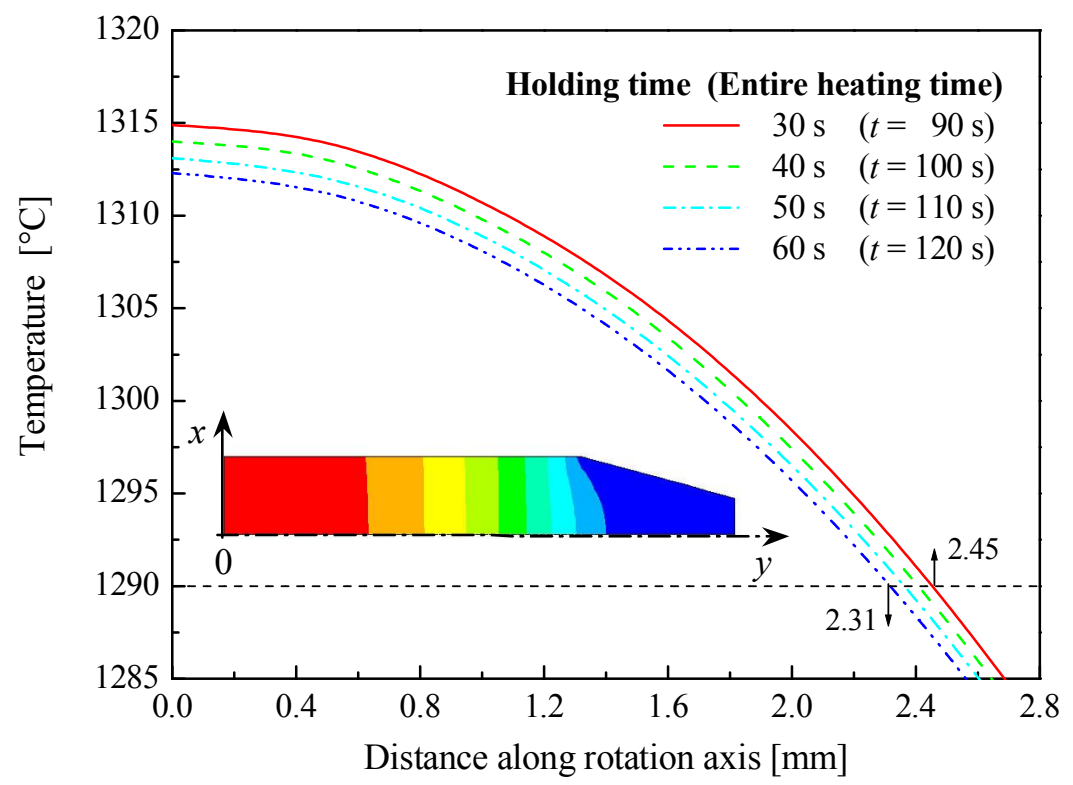

Fig. 10. Dependence of temperatures along rotation axis for chosen holding times

\subsection{Influence of geometrical characteristics of a semiproduct}

In the following step, the influence of semiproduct geometry on the temperature distribution and on the volume of semi-solid material was examined. Three semiproducts with the length of $40 \mathrm{~mm}, 38 \mathrm{~mm}$ a $36 \mathrm{~mm}$ (Fig. 3a) were compared by the loading with the same voltage. It is clear that the heating of the shortest semiproduct is the fastest (Fig. 11). The heating time to the solidus temperature is ranging from $40.7 \mathrm{~s}$ to $50.8 \mathrm{~s}$ for the semiproduct with maximum dimensions.

The volume of semi-solid material increases from $113 \mathrm{~mm}^{3}$ to approximately $150 \mathrm{~mm}^{3}$ (Table 3). From this volume, about $61 \%$ of material is heated to the required temperature interval from $1290^{\circ} \mathrm{C}$ to $1330^{\circ} \mathrm{C}$. 


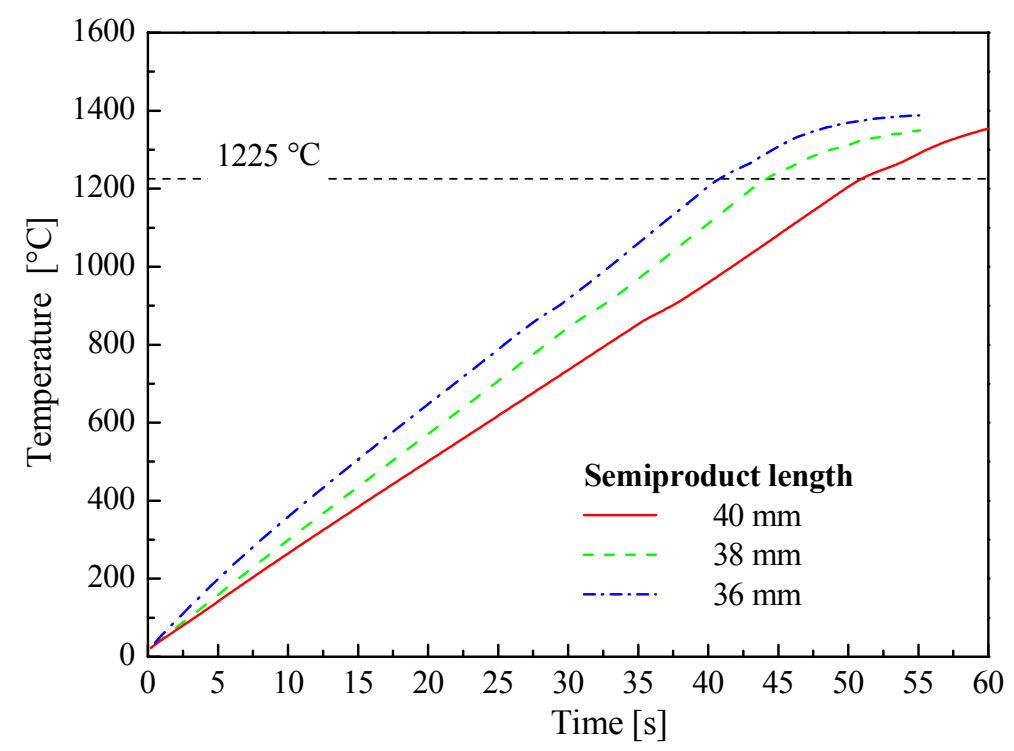

Fig. 11. Time history of temperature in the centre of gravity of semiproducts

Table 3. Dependence of the volume of semi-solid material on the semiproduct length

\begin{tabular}{|l|c|c|c|}
\hline \multirow{2}{*}{ Volume of the material with the temperature } & \multicolumn{3}{|c|}{ Length of a semiproduct } \\
\cline { 2 - 4 } & $\mathbf{4 0 ~} \mathbf{~ m}$ & $\mathbf{3 8} \mathbf{~ m m}$ & $\mathbf{3 6} \mathbf{~ m m}$ \\
\hline above solidus temperature $\left[\mathrm{mm}^{3}\right]$ & 149.71 & 127.23 & 113.09 \\
\hline in the interval from $1290^{\circ} \mathrm{C}$ to $1330^{\circ} \mathrm{C}\left[\mathrm{mm}^{3}\right]$ & 91.48 & 80.30 & 70.68 \\
\hline
\end{tabular}

The mushy zones with the temperatures from the range from $1225^{\circ} \mathrm{C}$ to $1330^{\circ} \mathrm{C}$ in the semiproducts with different lengths are illustrated in Fig. 12. According to the volume of material with the temperature above solidus temperature of $1225^{\circ} \mathrm{C}$, the semiproduct with the length of $40 \mathrm{~mm}$ is recommended for the following experimental forming in semi-solid state.

a)

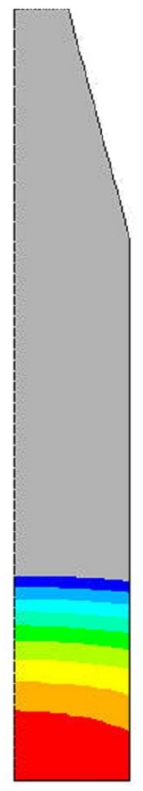

b)

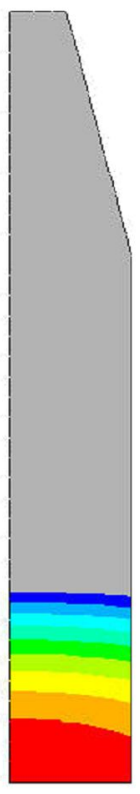

c)

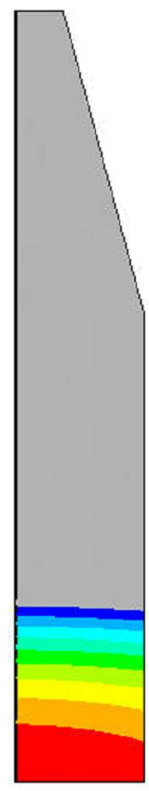

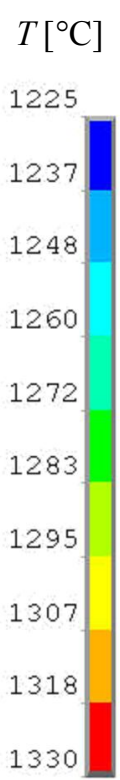

1330

Fig. 12. Mushy zone with the temperatures from the range from $1225^{\circ} \mathrm{C}$ to $1330^{\circ} \mathrm{C}$ in the semiproduct with the length of a) $40 \mathrm{~mm}$, b) $38 \mathrm{~mm}$ and c) $36 \mathrm{~mm}$ 


\section{Conclusion}

The paper deals with modeling and numerical simulation of temperature fields by direct electric heating of semiproducts from the $\mathrm{X} 210 \mathrm{Cr} 12$ steel before their forming in semi-solid state. Based on the developed and verified simulation model, numerical analysis of electric and temperature fields by the program code ANSYS 10.0 was performed. Virtual testing of material heating was aimed at the evaluation of the influence of chosen parameters (heating rate, holding time and geometric characteristics of semiproducts) on the temperature distribution in the heated semiproduct and the volume of semi-solid material at the end of heating.

Contrary to the real experiment during which temperatures can be measured only in the single point at the semiproduct surface, numerical experiments and computer simulation enable deeper insight into the investigated process of electric heating. Performed virtual (numerical) testing of material heating represents initial studies providing the basic idea of temperature distribution in a heated semiproduct. Based on the obtained results, parameters of direct electric heating for the process of forming in semi-solid state will be modified and experimentally tested.

\section{Acknowledgment}

The research has been supported by VEGA MS and SAV of the Slovak Republic within the project No. 1/0837/08.

\section{References}

[1] Flemings, M. C., Semi-solid forming: the process and the path forward. Metallurgical Science and Technology, Vol. 18 (2) (2000), pp. 1-4.

[2] Kiuchi, M. and Kopp, R., Mushy/Semi-Solid Metal Forming Technology - Present and Future, CIRP Annals - Manufacturing Technology, Vol. 51, Issue 2, (2002), pp. 653670.

[3] Hirt, G., Shimahara, H., Seidl, I., Kuthe, F., Abel, D. and Schonbohm, A., Semi-Solid Forging of 100Cr6 and X210CrW12 Steel, CIRP Annals - Manufacturing Technology, Vol.54, Issue 1, (2005), pp. 257-260.

[4] Bendada, A., Zheng, C. Q. and Nardini, N., Investigation of temperature control parameters for inductively heated semi-solid light alloys using infrared imaging and inverse heat conduction, J. Phys. D: Appl. Phys. 37 (2004) 1137-1144.

[5] Muenstermann, S., et al., Semi-solid extrusion of steel grade X210CrW12 under isothermal conditions using ceramic dies, J. Mater. Process. Tech. (2008), doi:10.1016/ j.jmatprotec.2008.08.040.

[6] Püttgen, W., Hallstedt, B., Bleck, W. and Uggowitzer, P. J., On the microstructure formation in chromium steels rapidly cooled from the semi-solid state, Acta Materialia, Vol. 55, Issue 3, (2007), pp. 1033-1042.

[7] Stanková, H., Klauberová, D., Ronešová, A. and Mašek, B., Influence of Thixoforming on Structure Development of the Tool Steel, In 12th International Research/Expert Conference - TMT 2008, Turkey, 26. - 30. August, 2008.

[8] Bramann H., Fehlbier, M., Sahm, P.R. and Bührig-Polaczek A., Casting of a cold work steel alloy in semi-solid state, Journal of Materials Processing Technology 155-156 (2004) 1357-1364.

[9] Song, R., Kang, Y. and Zhao, A., Semi-solid rolling process of steel strips, Journal of materials processing technology 198 (2008) 291-299.

[10] Ansys Theoretical Manual, Release 10.0, SAS IP, Inc., (2005). 
[11] Behúlová, M., Staňková, H. and Mašek, B., Analysis of temperature distribution in samples by direct electric heating, In Materials Science and Technology [online]. (http://web.mtf.stuba.sk/sk/casopis/index.htm), Vol. 7, No. 1, 2007.

[12] Taraba, B., Numerical analysis of temperature fields and its application in chosen technological processes. Assoc. Prof. Graduation Work, TU Košice, 2003.

[13] Novák, P., Základy elektrotepelnej techniky, Mercury-Smekal Košice, 2001.

[14] Incropera, F. P. and De Witt, D. P., Fundamentals of heat and mass transfer, J. Wiley and Sons New York, 1996.

[15] Taraba, B., Behúlová, M. and Kraváriková, H., Mechanika tekutín, termomechanika. Bratislava: STU, 2004.

[16] Ražnjevič, K., Termodynamické tabul'ky. Alfa, Bratislava, 1983.

[17] www.matweb.com (1.12.2008) 